44 (1) | 2015

Varia

Lima, 16-18 de abril de 2015

\title{
Seminario Taller del GRDI «APOCAMO»: «El fetichismo de lo jurídico en el movimiento político indígena amazónico»
}

Alexandre Surrallés

(2) OpenEdition

Journals

Edición electrónica

URL: http://journals.openedition.org/bifea/7464

DOI: 10.4000/bifea.7464

ISSN: 2076-5827

Editor

Institut Français d'Études Andines

Edición impresa

Fecha de publicación: 1 abril 2015

Paginación: 175-180

ISSN: 0303-7495

Referencia electrónica

Alexandre Surrallés, « Seminario Taller del GRDI «APOCAMO»: «El fetichismo de lo jurídico en el movimiento político indígena amazónico» », Bulletin de l'Institut français d'études andines [En línea], 44 (1) | 2015, Publicado el 08 mayo 2015, consultado el 05 noviembre 2020. URL : http:// journals.openedition.org/bifea/7464; DOI : https://doi.org/10.4000/bifea.7464

\section{(c) (i) $\odot$}

Les contenus du Bulletin de l'Institut français d'études andines sont mis à disposition selon les termes de la licence Creative Commons Attribution - Pas d'Utilisation Commerciale - Pas de Modification 4.0 International. 


\section{SEMINARIO TALLER DEL GRDI «APOCAMO»1: «EL FETICHISMO DE LO JURÍDICO EN EL MOVIMIENTO POLÍTICO INDÍGENA AMAZÓNICO»}

Lima, 16-18 de abril de 2015

Las organizaciones indígenas han dedicado una buena parte de su tiempo y energía al reconocimiento y promoción de sus derechos, tanto a nivel consuetudinario, nacional como internacional. $\mathrm{Y}$ al mismo tiempo se han apropiado del lenguaje y de los instrumentos jurídicos para defender sus derechos y sus costumbres, incluyendo el derecho a la administración de justicia tradicional. De esta manera han conseguido alzar un imponente edificio jurídico que culmina con la famosa Declaración de las Naciones Unidas sobre el derecho de los pueblos indígenas de 2007 que declara, nada más y nada menos, que la libre determinación de

1 Grupo de Investigación internacional (GDRI) APOCAMO «Antropología política contemporánea en la Amazonía occidental» (IFEA, CNRS, EHESS, UNAL, PUCP, FLACSO). 
los pueblos indígenas en los espacios territoriales que ocupan o hayan ocupado.

Es cierto que los derechos de los pueblos indígenas en los diferentes países andinos se encuentran a muy distintos niveles de desarrollo, y esto independientemente del carácter del régimen político que gobierna hoy en cada uno. Hay países que reconocen grandes espacios territoriales con sistemas de gobierno autóctonos. Otros se contentan con reconocimientos comunitarios negando a los pueblos indígenas la calidad de sujetos de derecho. Sin embargo, a pesar de estas diferencias considerables, el mapa del avance del frente extractivo y sus consecuencias en términos de degradación ambiental y social para los pueblos indígenas y su entorno son similares.

Si los avances en la legislación no parecen significar unas mejoras concretas, podemos hacernos varias preguntas en torno a la relación

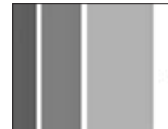

Grupo de Investigación internacional (GDRI) APOCAMO "Antropologia politica contemporánea en la Amazonia occidental" (IFEA, CNRS, EHESS, UNAL, PUCP, FLACSO)
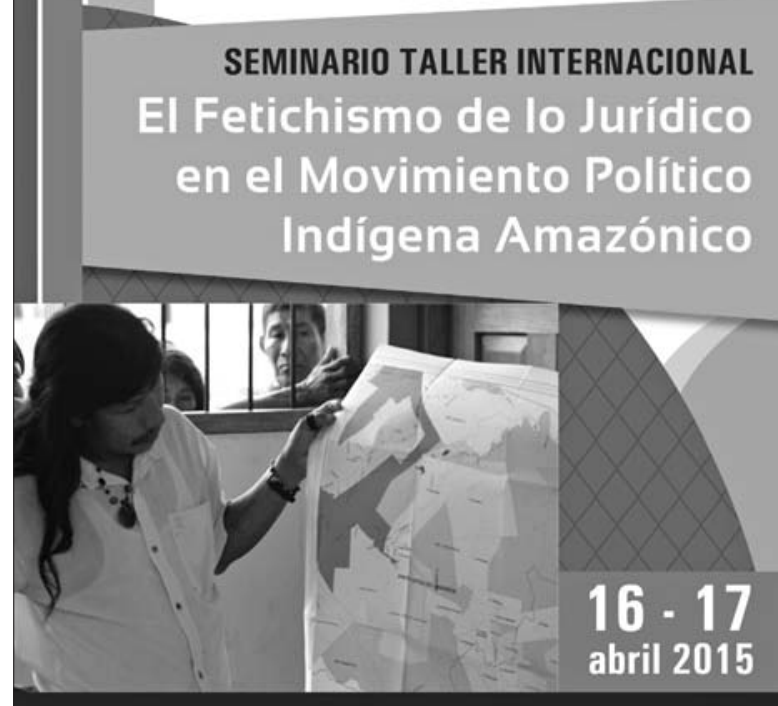

Lugar: Sala de Grados de la Facultad de Ciencias Sociales, PUCP ENTRADA LIBRE

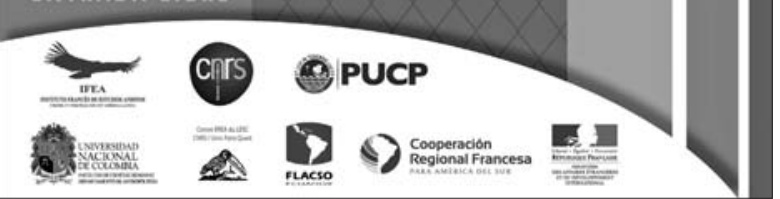
entre el derecho y sus usos que están teniendo actualmente en las sociedades amazónicas. Con el objetivo sobretodo de bien formular estas preguntas, de encontrar algunas respuestas, y explorar así el balance y las consecuencias del interés que las organizaciones políticas indígenas y sus líderes tienen en el derecho, el séptimo seminario-taller del grupo Apocamo tuvo lugar los pasados días 16 y 17 de abril de 2015, en Lima, en la Sala de Grados de la Facultad de Ciencias Sociales de la PUCP.

Las palabras de bienvenida fueron ofrecidas por Alejandro Diez, Jefe del Departamento de CCSS (PUCP), y Gérard Borras, director del Instituto Francés de Estudios Andinos-IFEA, en nombre de las instituciones que una vez más tuvieron a bien promover y albergar este taller con vocación itinerante puesto que la pasada reunión se desarrolló en La Paz. A continuación tomaron la palabra los organizadores de este seminario-taller, Oscar Espinosa (PUCP), y yo mismo (Alexandre Surrallés, CNRS-IFEA), para presentar el marco argumental, los objetivos del encuentro y el programa, que se dividía en dos secciones, un día para cada una.

El jueves y bajo el titulo genérico de «Ley, poder y violencia» empezó el taller propiamente dicho con la ponencia inaugural del Prof. Fernando García Serrano 
de la Flacso-Ecuador con una presentación titulada «Muerte y venganza entre los waorani y tagaeri/taromenane de la amazonia ecuatoriana: un caso de fetichismo jurídico o justicia intercultural?» La presentación analizó el caso de la muerte de dos ancianos waorani, ompore omewai y buganei caiga, en la comunidad de Yarentaro el 5 de marzo de 2013 por parte de guerreros tagaeri/taromenane pertenecientes a pueblos ecuatorianos en aislamiento, y que provocó una incursión de 17 guerreros en busca de venganza que supuestamente mataron a un número indeterminado de aislados a fines de marzo del mismo año. La única evidencia de este hecho lo constituyen dos niñas que fueron raptadas por los atacantes y que viven actualmente en dos comunidades waorani. La Fiscalía General inició un proceso jurídico contra los 17 guerreros acusándoles de etnocidio y genocidio. El análisis de Fernando García se centró sobre cómo las diversas acciones legales llevadas a cabo en el transcurso de 2013 y 2014 enfrentaron a los waorani con el sistema jurídico ordinario ecuatoriano, planteando nuevos retos para su resolución. La ponencia analizó en particular de qué manera la resolución de un conflicto interno entre dos pueblos indígenas es atravesada por la injerencia de la justicia ordinaria. En particular, cómo su significado y uso funciona a favor o en contra de sus derechos colectivos como pueblo, convirtiendo la ley en un fetiche y desplazando de esta manera un conflicto político hacia el terreno de lo jurídico. Antes de dejar paso a las intervenciones de los otros miembros de Apocamo presentes en la sala, y otros participantes, tomaron la palabra Jean-Pierre Chaumeil (CNRS-LESC-EREA) y Eduardo Fernández (PUCP) para unos primeros comentarios sobre esta ponencia clave para el tema abordado en este taller.

Después de una pausa, fue el turno de Simone Garra, doctorando en la Université Paris-Ouest Nanterre La Défense, con una presentación titulada: «El "hacer documentos" como medio de acción e instrumento de poder en la sociedad awajún contemporánea». Desde la creación de las primeras «comunidades nativas» (1974), los awajún de la región de Condorcanqui han ido aprendiendo a manejar el lenguaje jurídico-administrativo del Estado para interactuar con él y obtener el reconocimiento de sus tierras organizándose a imagen y semejanza de las instituciones de la democracia representativa y sus principios. Simone Garra analiza cómo en este contexto, el «hacer documentos» se vuelve una habilidad cada vez más importante en las relaciones inter- e intraétnicas, particularmente en situaciones de conflicto. La pregunta era hasta qué punto el Estado ha logrado moldear esta sociedad a través de crear esta dependencia al documento, obligándola a adoptar su ideología y sus prácticas. Para contestar a esta pregunta, se analizaron una serie de actas y certificados producidos por los awajún, en los que se pone de manifiesto la interacción constante que existe entre la legitimidad establecida por un principio colectivo abstracto y la dinámica siempre presente de manipulación de los rumores por parte de los individuos. En otras palabras, Simone Garra nos avanzó la idea según la cual «el hacer documentos» constituye hoy la arena de una problemática conciliación entre la lógica eurocéntrica del Derecho y los valores que rigen las relaciones interpersonales entre los awajún. Los comentarios de Oscar Espinosa (PUCP) y Erik Pozo (PUCP) dejaron paso a las intervenciones de la sala antes del receso del mediodía. 
Por la tarde la Prof. ${ }^{a}$ Andrea-Luz Gutiérrez Choquevilca de la EPHE, nos presentó un aporte cuyo título fue «El "caso Andoas", entre plumas y petróleo. Procesos de criminalización y revitalización de la protesta indígena de los runa del Pastaza». Según relató la ponente, el 18 de junio de 2012, en el territorio quechua del Pastaza del Oriente Peruano, un leader runa se dirigió al Presidente del gobierno regional loretano con esas palabras: «Apu Yván escúchanos, nosotros somos los pueblos! iTambién como te hemos puesto, te podemos sacar!», subrayando la posible e inminente destitución del jefe por el poder de la asamblea y la soberanía indígena... A partir de este acto, la ponencia examinó la complejidad de las representaciones indígenas del poder jurídico y los procesos internos de revitalización política del pueblo quechua del Pastaza, a través de las interacciones con el Estado y la Compañía Pluspetrol N. C., desde la criminalización de la protesta indígena en el caso Andoas (2008). A partir de un enfoque denominado «pragmático», el análisis se centró en las dinámicas de construcción de las nuevas formas de legitimidad indígena así como en las incertidumbres epistemológicas acerca de la representación del derecho y del concepto ambiguo de ciudadanía indígena. Después de las aportaciones de Fernando García (Flacso-Ecuador) e Ismael Vega (CAAAP) se pasó la palabra a la audiencia antes de una pausa.

Para terminar la jornada, la Prof. ${ }^{a}$ Ivette Vallejo de la Flacso-Ecuador continuó con una intervención titulada: «Shamanismo, petróleo e itinerarios legales inconclusos en la Amazonía» donde abordó el intrincado entrelazamiento entre dos dimensiones a priori alejadas entre sí como pueden ser el shamanismo y el capital en contextos extractivos en la Amazonía ecuatoriana. Se analizó cómo en el presente la predación mercantil de la naturaleza que conlleva el extractivismo,

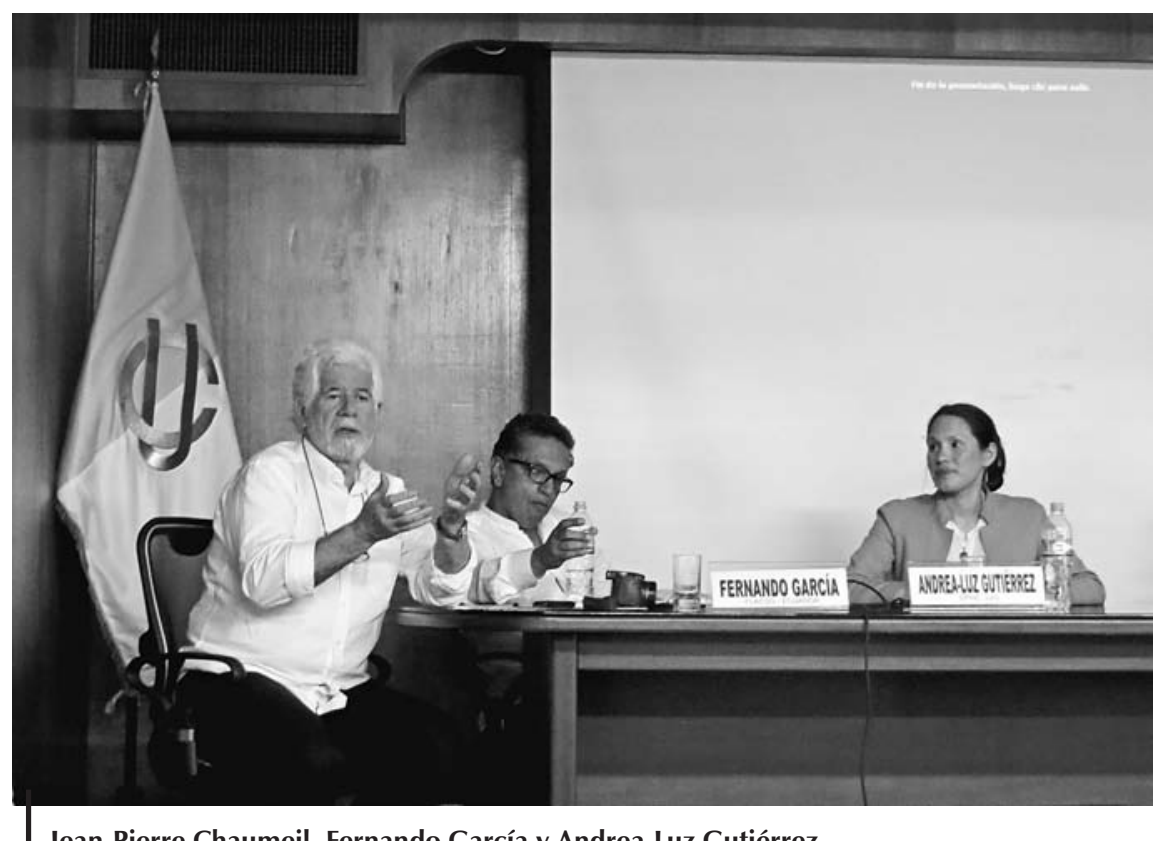

Jean-Pierre Chaumeil, Fernando García y Andrea-Luz Gutiérrez 
acentúa la conflictividad interna en comunidades indígenas amazónicas, activando enfrentamientos, amenazas y muerte por shamanismo, en medio de diferentes posicionamientos sobre la aceptación de la actividad petrolera y disputas por el acceso a la distribución de regalías o compensaciones por parte del Estado. La presentación se centro en explicar cómo dentro de este marco los/as indígenas amazónicos efectúan itinerarios legales ante instancias de la justicia ordinaria, sin que sus demandas ante muertes por shamanismo sean procesadas, al no tener cabida dentro de la tipificación de delitos. Esta falta de respuesta del sistema de justicia estatal encauza nuevas tramas dentro de las formas internas de procesamiento de los conflictos con consecuencias a veces lamentables. Alexandre Surrallés (CNRS-IFEA) y Giancarlo Rolando (PUCP-U. Virginia) comentaron la ponencia antes de dar paso a los comentarios de la sala.

Durante el segundo día, y según estaba previsto, se abordaron algunos estudios bajo la rubrica del título «Derecho como aspiración». Silvia Romio, doctoranda en la EHESS empezó el día con una presentación titulada «El juicio del Baguazo: el largo desencuentro entre la justicia occidental y las perspectivas awajún y wampís» sobre el juicio penal del enfrentamiento denominado «el Baguazo», caso paradigmático de la política de criminalización de la protesta amazónica. La ponente analizó las premisas de un juicio donde los acusados son culpables y víctimas a la vez, y donde los límites y la falta de preparación de un sistema judicial —denominado por Romio «occidental»- para enfrentar un caso de interculturalidad. El análisis quiso mostrar cómo la Sala Penal de Bagua no juzgaba solamente a los acusados, sino a todo el pueblo indígena awajún y wampís, por lo que podríamos llamar su «código» militar y civil, y más generalmente por toda su cultura. La ponencia se centró al final en examinar las percepciones de los representantes de los awajún frente a este proceso, para mostrar el profundo «desencuentro» entre lenguaje judicial y perspectivas indígenas. Oscar Espinosa (PUCP) y Jean-Pierre Chaumeil (CNRS-LESC-EREA) ofrecieron sendos comentarios que precedieron las intervenciones de la audiencia.

A continuación yo mismo tomé la palabra con una presentación titulada «Leyes universales, territorios indígenas y paradojas históricas: awajún, shawi y shiwilu» donde examiné las diferencias en las posiciones de tres pueblos indígenas de la Amazonía peruana vecinos entre ellos, posteriores a los procesos de demanda de territorio único integral siguiendo la estela de la Declaración de la Asamblea Naciones Unidas sobre el derecho de los Pueblos indígenas. Estos pueblos han autodemarcado un territorio cuyos límites han negociado con sus vecinos y se han dotado de informes antropológicos y jurídicos que sostienen esta demanda. Hasta aquí los tres pueblos han seguido pasos similares. Sin embargo, en el momento posterior de plantear acciones concretas como la de dirigirse al Estado y determinar la demanda, han surgido diferencias sin duda producidas por la relación de cada pueblo con la história de relaciones entre ellos y con el frente colonial. La propuesta awajún es convertir estos territorios integrales en una demarcación del Estado, algo que los shiwilu consiguieron ya en la Colonia con solo avenirse con el poder; es decir, sin Declaraciones universales, luchas políticas, ni constructos jurídicos. Esta paradoja, arroja un abismo de reflexiones que mi intervención 
quiso desgranar sin agotar por supuesto los múltiples aspectos que esta situación arroja y el carácter anacrónico de la comparación. Los comentarios de Gil Inoach, ex presidente de Aidesep y Frederica Barclay (PUCP) precedieron el conversatorio con todos los presentes.

Para terminar las presentaciones y por la tarde, la Dra. Céline Valadeau, investigadora del Instituto Francés de Estudios Andinos-IFEA, presentó una ponencia titulada «De un convenio de recolección de muestras vegetales a la creación del Instituto de etnobotánica yanesha: estudio de caso en la selva central (Perú)». Céline Valadeau analizó el caso del Instituto de Etnobotánica Yanesha (IEBY) nacido en 2012, después de un estudio etnobotánico que se desarrolló durante 4 años en unas comunidades yanesha de la selva central. En la ponencia se relató la cronología, examinando diferentes aspectos que envolvieron su creación. Dos aspectos fueron tratados especialmente: cómo apareció la necesidad de crear esta asociación comunal y cómo, de la misma forma que los programas de manejo ambiental y de desarrollo sostenible o las asociaciones de estudios botánicos, las evocaciones de una biodiversidad robada influyeron en este proceso. También se analizó la influencia en este proceso del propio trabajo realizado por la autora de la presentación. Fernando Roca (PUCP) e Ivette Vallejo (Flacso-Ecuador) comentaron la ponencia antes de pasar la palabra a los participantes. Unas conclusiones generales por parte de los organizadores, Oscar Espinosa y yo mismo, y un debate plenario posterior dieron paso a la clausura agradeciendo a la PUCP, la acogida y hospitalidad brindada.

Por la mañana del día 18 de abril, y a puerta cerrada, tuvo lugar la reunión interna de los miembros del GRDI «Apocamo» en cuyo orden del día figuraba la preparación del próximo seminario-taller así como el examen de solicitud de nuevos miembros. 